\title{
STOCHASTIC MATHEMATICAL MODEL OF INTERNAL WAVES
}

\author{
E.V. Bychkov ${ }^{1}$, A.V. Bogomolov ${ }^{2}$, K.Yu. Kotlovanov ${ }^{1}$ \\ ${ }^{1}$ South Ural State University, Chelyabinsk, Russian Federation, \\ ${ }^{2}$ Saint Petersburg Institute for Informatics and Automation of RAS, Saint Petersburg, \\ Russian Federation \\ E-mails: bychkovev@susu.ru, a.v.bogomolov@gmail.com, kotlovanovki@susu.ru
}

\begin{abstract}
The paper studies a mathematical model of internal gravitational waves with additive "white noise", which models the fluctuations and random heterogeneity of the medium. The mathematical model is based on the Sobolev stochastic equation, Dirichlet boundary conditions and the initial Cauchy condition. The Sobolev equation is obtained from the assumption of the propagation of waves in a uniform incompressible rotation with a constant angular velocity of the fluid. The solution to this problem is called the inertial (gyroscopic) wave, since it arises due to the Archimedes's law and under the influence of inertia forces. By "white noise" we mean the Nelson-Gliklikh derivative of the Wiener process. The study was conducted in the framework of the theory of relatively bounded operators, the theory of stochastic equations of Sobolev type and the theory of (semi) groups of operators. It is shown that the relative spectrum of the operator is bounded, and the solution of the Cauchy-Dirichlet problem for the Sobolev stochastic equation is constructed in the operator form.

Keywords: relatively bounded operator; Sobolev equation; propagators; "white noise"; Nelson-Gliklikh derivative.
\end{abstract}

\section{Introduction}

The internal waves arise at the interface of two fluids with different densities. In internal waves the maximum vertical displacement of particles takes place not on the surface of the fluid, but inside it. For example, this fact can be observed in the ocean at the location of desalinated water over heavier water with greater salinity. In this place a part of power of the ship engine is consumed on excitation of internal waves, resulting in a decrease of sheep's speed. In the simplest case the two-layer fluid model of internal waves is quite similar to the surface waves. They also concentrate near the interface. Assuming that the fluid fills entirely each half space on both sides of the border, the dispersion relation for internal waves is identical to the dispersion relation $\omega^{2}=g k$, where $g$ is the acceleration due to gravity and $k$ is the wavenumber, for gravitational waves but with a different effective value gravity acceleration [1].

The mathematical model of waves in homogeneous incompressible fluid rotating with a constant angular velocity $\Omega$ is described by the linear system of hydrodynamic equations (the Sobolev system of equations [2])

$$
\left\{\begin{array}{l}
\nu_{t}+\frac{1}{\rho_{0}} \nabla p+2[\Omega \times \nu]=0, \\
\rho_{t}=0 \\
\nabla \nu=0
\end{array}\right.
$$

where $\nu=\{u, v, w\}$ is a vector of velocity, $p$ is a pressure is applied perpendicular to the free surface, $\rho_{0}=$ const is an equilibrium density, and the buoyancy frequency is equal to zero. By directing the $O z$ axis to be collinear to the vector of $\Omega$, we can obtain the equation for the vertical velocity component of the fluid particles (the Sobolev equation [2]) 


$$
\Delta w_{t t}+F^{2} w_{z z}=0
$$

where $F$ is the Coriolis parameter. The wave solutions that satisfy (2) are called inertial (or gyroscopic) waves propagating on the surface of a rotating fluid. A solution to equation (2) in an unbounded domain was obtained in [2] by the Green function method. The paper [3] describes the behavior of solutions to two-dimensional Hamiltonian systems arising in the theory of small oscillations of rotating ideal fluid and constructs a mathematical model of the incipience of a vortex structure.

In this paper, we study the inhomogeneous stochastic equation

$$
\Delta \stackrel{\circ}{w}_{t t}+F^{2} w_{z z}=\stackrel{\circ}{f}_{K}
$$

with the initial-boundary conditions

$$
\begin{gathered}
w(x, t)=0, \quad(x, t) \in \partial D \times \mathbb{R}, \\
w(x, 0)=w_{0}(x), \quad \stackrel{\circ}{w}_{t}(x, 0)=w_{1}(x),
\end{gathered}
$$

where $\stackrel{\circ}{w}_{t}\left(\stackrel{\circ}{w}_{t t}\right)$ is the first (second) Nelson-Gliklikh derivative of a random process $w, \stackrel{\circ}{f}_{K}(t)$ is the "white noise", which models heterogeneity of fluid and random fluctuations, $D \subset \mathbb{R}^{3}$ is a domain with a smooth boundary $\partial D, w_{0}(x)$ and $w_{1}(x)$ are random $K$-variables. By "white noise" we mean the Nelson-Gliklikh derivative of the Wiener process.

The concept of the Nelson-Gliklikh derivative was introduced in the monograph [4]; the first derivative of an arbitrary random process was also found there. Later, derivatives of higher-order random processes were calculated, and the first mathematical models with "white noise", were investigated [5]. The Nelson-Gliklikh derivative is based on the concept of the average derivative introduced by Nelson [6]. In addition to the approach to "white noise", as the Nelson-Gliklikh derivative, the Ito-Stratonovich-Skorokhod approach is used by Kovac and Larson [7]. Also, in [8], a equation of the parabolic type was considered in the form of Ito differentials with uniform initial conditions, and a solution to the problem was found by reducing the equation to a first-order system. I.V. Melnikova takes a similar approach. The paper [8] introduces the spaces of generalized $H$-valued random variables, in which the $H$-valued white noise turns out to be smooth with respect to the variable $t$. It was shown in [9] that the Nelson-Gliklikh derivative of the Wiener process is in good agreement with the predictions of the Einstein - Smoluchowski theory of Brownian motion; therefore, the stochastic process was called "white noise". This approach is successfully applied to the study of equation of the Sobolev type, mathematical model based on one [10-15], the dichotomies of the stochastic equation defined on the manifold [16], and to the study of mathematical models of measuring devices [9].

The paper is organized as follows. In Section 1, we define the space of random $K-$ variables, the space of random $K$-"process", and the space of $K$-"noises". In Section 2, we introduce the basic definitions and concepts of the relatively bounded operators theory and findings the solution of abstract equation. In Section 3, the mathematical model is reduced to the Cauchy problem for an abstract operator-differential equation and the propagators for stochastic Sobolev equation (3) are constructed when $D$ is a parallelepiped.

\section{Space of Differentiable $K-$ "noises"}

Currently, the theory of Sobolev type equations is transferred to the spaces of $K$ "noises" [9-16]. In this section, for completeness, we give only the necessary information about the spaces of differentiable $K$-"noises", which are considered in $[9,16]$. Denote by 
$\Omega \equiv(\Omega, A, P)$ the total probability space. A measurable map $\xi: \Omega \rightarrow \mathbb{R}$ is called a random variable. The set of random variables whose expectations are equal to zero (i.e., $E \xi=0$ ) and the variances are finite (i.e., $D \xi<+\infty$ ) forms the Hilbert space $\mathbf{L}_{\mathbf{2}}$ with the inner product $\left(\xi_{1}, \xi_{2}\right)=E \xi_{1} \xi_{2}$. Denote by $A_{0}$ a $\sigma$-subalgebra of the $\sigma$-algebra $A$ and construct the space $\mathbf{L}_{2}^{\mathbf{0}}$ of random variables measurable with respect to $A_{0}$, then $\mathbf{L}_{2}^{\mathbf{0}}$ is a subspace of the space $\mathbf{L}_{\mathbf{2}}$. Let $\xi \in \mathbf{L}_{\mathbf{2}}$, then $\Pi: \mathbf{L}_{\mathbf{2}} \rightarrow \mathbf{L}_{\mathbf{2}}^{\mathbf{0}}$ is an orthoprojector, and $\Pi \xi$ is called the conditional expectation of a random variable $\xi$ and denoted by $E\left(\xi \mid A_{0}\right)$.

Let $I=(0, T), T \in \mathbb{R}_{+}$. Consider two mappings: $f: I \rightarrow \mathbf{L}_{\mathbf{2}}$, which associates each $t \in I$ with a random variable $\xi \in \mathbf{L}_{\mathbf{2}}$, and $g: \mathbf{L}_{\mathbf{2}} \times \Omega \rightarrow \mathbb{R}$, which associates each pair $(\xi, \omega)$ with a point $\xi(\omega) \in \mathbb{R}$. The map $\eta: I \times \Omega \rightarrow \mathbb{R}$ of the form $\eta=\eta(t, \omega)=g(f(t), \omega)$ is called (one-dimensional) random process. If all the trajectories of a random process are almost surely (a.s.) continuous, then this process is called continuous. The set of continuous random processes forms a Banach space, which we denote by $\mathbf{C L}_{\mathbf{2}}$. An example of a continuous random process is the one-dimensional Wiener process $\beta=\beta(t)$, which can be represented as

$$
\beta(t)=\sum_{k=0}^{\infty} \xi_{k} \sin \left(\frac{\pi}{2}(2 k+1) t\right),
$$

where $\xi_{k}$ are uncorrelated Gaussian random variables such that $E \xi_{k}=0, \quad D \xi_{k}=$ $\left[\frac{\pi}{2}(2 k+1)\right]^{-2}$.

Now we fix an arbitrary continuous random process $\eta \in \mathbf{C L}_{\mathbf{2}}$ and $t \in I$. Let $N_{t}^{\eta}$ be the $\sigma$-algebra generated by the random process $\eta(t)$, and $E_{t}^{\eta}=E\left(\cdot \mid N_{t}^{\eta}\right)$ be the conditional expectation.

Let $\eta \in \mathbf{C L}_{\mathbf{2}}$, then by the average derivative from the right $D \eta(t, \cdot)\left(\right.$ left $\left.D_{*} \eta(t, \cdot)\right)$ of the random process $\eta$ at the point $t \in(\varepsilon, \tau)$ we mean a random variable

$$
\begin{aligned}
D \eta(t, \cdot) & =\lim _{\Delta t \rightarrow 0+} E_{t}^{\eta}\left(\frac{\eta(t+\Delta t, \cdot)-\eta(t, \cdot)}{\Delta t}\right) \\
\left(D_{*} \eta(t, \cdot)\right. & \left.=\lim _{\Delta t \rightarrow 0+} E_{t}^{\eta}\left(\frac{\eta(t, \cdot)-\eta(t-\Delta t, \cdot)}{\Delta t}\right)\right),
\end{aligned}
$$

if the limit exists in the sense of the uniform metric on $\mathbb{R}$. A random process $\eta$ is called average differentiable from the right (left) on $I$ if there exists an average derivative from the right (left) at each point $t \in I$. Let $\eta \in \mathbf{C L}_{\mathbf{2}}$ be a random process, which is average differentiable from the right and left on $I$. Then the average symmetric derivative is defined as $\stackrel{\circ}{\eta}=D_{S} \eta=\frac{1}{2}\left(D+D_{*}\right) \eta$. Further, we refer to the average symmetric derivative as the Nelson-Gliklikh derivative. By $\stackrel{\circ}{\eta}^{(l)}, l \in \mathbb{N}$, we denote the $l$-th Nelson-Glicklikh derivative of the random process $\eta$. Note that if $\eta(t)$ is a deterministic function, then the NelsonGliklikh derivative coincides with the classical derivative. In the case of the one-dimensional Wiener process $\beta=\beta(t)$, the following statements are true:

(i) $\stackrel{\circ}{\beta}(t)=\frac{\beta(t)}{2 t}$ for all $t \in \mathbb{R}_{+}$;

(ii) $\stackrel{\circ}{\beta}^{(l)}(t)=(-1)^{l-1} \prod_{i=1}^{l-1}(2 i-1) \frac{\beta(t)}{(2 t)^{l}}, \quad l \in \mathbb{N}, \quad l \geq 2$.

We construct the noise space $\mathbf{C}^{\mathbf{l}} \mathbf{L}_{2}, l \in \mathbb{N}$, as the space of random processes from $\mathbf{C L}_{\mathbf{2}}$, whose trajectories are almost sure differentiable in the sense of the Nelson-Gliklikh derivative on $I$ up to the $l$-th order inclusive. 
Let $\mathfrak{U}$ be a separable Hilbert space with the orthonormal basis $\left\{\varphi_{k}\right\}$. Each element $u \in \mathfrak{U}$ can be written as

$$
u=\sum_{k=1}^{\infty} u_{k} \varphi_{k} .
$$

Let $K=\left\{\nu_{k}\right\}$ be a monotonically decreasing numerical sequence such that $\sum_{k=1}^{\infty} \nu_{k}^{2}<+\infty$. Choose a sequence of random variables $\left\{\xi_{k}\right\} \subset \mathbf{L}_{\mathbf{2}}$ such that $\sum_{k=1}^{\infty} \nu_{k}^{2} D \xi_{k}<+\infty$. Then a Hilbert space $\mathbf{U}_{\mathbf{K}} \mathbf{L}_{\mathbf{2}}$ is called a random $K$-variable space, moreover $\xi=\sum_{k=1}^{\infty} \nu_{k} \xi_{k} \varphi_{k}$.

Choose a sequence $\left\{\eta_{k}\right\}$ from the space $\mathbf{C L}_{2}$ and define the $\mathfrak{U}$-valued continuous random $K$-process by the formula

$$
\xi(t)=\sum_{k=1}^{\infty} \nu_{k} \xi_{k}(t) \varphi_{k}
$$

provided that series (7) converges uniformly on any compact set from $I$ in the norm of $\mathbf{U}_{\mathbf{K}} \mathbf{L}_{\mathbf{2}}$. We introduce the Nelson-Gliklikh derivatives of the random $K$-process $\stackrel{\circ}{\xi}^{(l)}(t)=$ $\sum_{k=1}^{\infty} \nu_{k} \stackrel{\circ}{\xi}_{k}^{(l)}(t) \varphi_{k}$ provided that the Nelson-Gliklikh derivatives from the right exist up to the $l$-th order inclusive, and all the series converge uniformly on any compact set of $I$ in the norm of $\mathbf{U}_{\mathbf{K}} \mathbf{L}_{\mathbf{2}}$. Therefore, we define the space $C^{l}\left(I ; \mathbf{U}_{\mathbf{K}} \mathbf{L}_{\mathbf{2}}\right)$ of continuous random $K$-processes whose trajectories are a.s. continuously differentiable with respect to NelsonGliklikh up to the $l$-th order inclusive. For shortness, the space $C^{l}\left(I ; \mathbf{U}_{\mathbf{K}} \mathbf{L}_{\mathbf{2}}\right)$ is called the space (of differentiable) K-"noises".

\section{Cauchy Problem for Abstract Stochastic Equation}

Let consider two spaces of random $K$-variable $\mathfrak{U}=\mathbf{U}_{\mathbf{K}} \mathbf{L}_{\mathbf{2}}, \mathfrak{F}=\mathbf{F}_{\mathbf{K}} \mathbf{L}_{\mathbf{2}}$, the operators $L, M, N \in \mathcal{L}(\mathfrak{U} ; \mathfrak{F})$, and $L$ be a Fredholm operator. Consider the Sobolev type equation of the second order in the space of differentiable $K$-"noises"

$$
L \stackrel{\circ}{w}_{t t}=M w+N g
$$

with the initial conditions

$$
\stackrel{\circ}{w}(0)=w_{0}, \quad \stackrel{\circ}{w}_{t}(0)=w_{1} .
$$

Using the following lemma, we can transfer the theory of relatively bounded operators to the spaces of random $K$-variables

Lemma 1. Let $U, F$ be separable Hilbert spaces and $A \in \mathcal{L}(U ; F)$. Then $A \in$ $\mathcal{L}\left(\mathbf{U}_{\mathbf{K}} \mathbf{L}_{2} ; \mathbf{F}_{\mathbf{K}} \mathbf{L}_{2}\right)$.

The sets

$$
\rho^{L}(M)=\left\{\mu \in \mathbb{C}:(\mu L-M)^{-1} \in \mathcal{L}(\mathfrak{F} ; \mathfrak{U})\right\}
$$

and $\sigma^{L}(M)=\mathbb{C} \backslash \rho^{L}(M)$ are called the L-resolvent set and L-spectrum of the operator $M$, respectively.

The operator $M$ is said to be $\sigma$-bounded with respect to the operator $L$ (or $(L, \sigma)$ bounded) if $\left.\exists a \in \mathbb{R}_{+}: \forall \mu \in \mathbb{C}(|\mu|>a) \Rightarrow(\mu L-M)^{-1} \in \mathcal{L}(\mathfrak{U} ; \mathfrak{F})\right)$.

The operator-functions $(\mu L-M)^{-1}, \quad R_{\mu}^{L}(M)=(\mu L-M)^{-1} L$ and $L_{\mu}^{L}(M)=L(\mu L-M)^{-1}$ with the domain $\rho^{L}(M)$ are called the $L$-resolvent, the right $L$-resolvent and the left $L$-resolvent of the operator $M$, respectively. If the set $\sigma^{L}(M)$ is bounded, then the operator $M$ is called $(L, \sigma)$-bounded. 
If the operator $M$ is $(L, \sigma)$-bounded, then the operators

$$
P=\frac{1}{2 \pi i} \int_{\gamma} R_{\mu}^{L}(M) d \mu \in \mathcal{L}(\mathfrak{U}), \quad Q=\frac{1}{2 \pi i} \int_{\gamma} L_{\mu}^{L}(M) d \mu \in \mathcal{L}(\mathfrak{F})
$$

exist. Here $\gamma \subset \mathbb{C}$ is a closed contour which bounds a domain containing $\sigma^{L}(M)$. Let $\mathfrak{U}^{0}\left(\mathfrak{U}^{1}\right)=\operatorname{ker} P(\operatorname{im} P), \mathfrak{F}^{0}\left(\mathfrak{F}^{1}\right)=\operatorname{ker} Q(\operatorname{im} Q)$. Denote by $L_{k}\left(M_{k}\right)$ the restriction of the operator $L(M)$ on the subspaces $\mathfrak{U}^{k}, k=0,1$.

Theorem 1. (The splitting theorem [10]) Let the operator $M$ be $(L, \sigma)$-bounded. Then

(i) the operators $L_{k}, M_{k} \in \mathcal{L}\left(\mathfrak{U}^{k}, \mathfrak{F}^{k}\right), k=0,1$;

(ii) there exist the operators $M_{0}^{-1} \in \mathcal{L}\left(\mathfrak{F}^{0}, \mathfrak{U}^{0}\right)$ and $L_{1}^{-1} \in \mathcal{L}\left(\mathfrak{F}^{1}, \mathfrak{U}^{1}\right)$.

Construct the operators $H=M_{0}^{-1} L_{0} \in \mathcal{L}\left(\mathfrak{U}^{0}\right), S=L_{1}^{-1} M_{1} \in \mathcal{L}\left(\mathfrak{U}^{1}\right)$. The operator $M$ is called $(L, p)$-bounded, $p \in\{0\} \cup \mathbb{N}$, if $\infty$ is a removable singularity of the $L$-resolvent of the operator $M$ (i.e. $H \equiv \mathbb{O}, p=0$ ) or a pole of the order $p(p \in \mathbb{N})$ (i.e. $H^{p} \neq \mathbb{O}$, $\left.H^{p+1} \equiv \mathbb{O}\right)$ of the $L$-resolvent of the operator $M$.

Definition 1. A random $K$-process $w \in C^{2}\left(I ; \mathbf{U}_{\mathbf{K}} \mathbf{L}_{\mathbf{2}}\right)$ is called a solution to equation (8), if a.s. all its trajectories satisfy equation (8) for all $t \in I$. A solution $w=w(t)$ of equation (8) is called a solution to problem (8), (9), if moreover condition (9) is fulfilled.

Note that, generally speaking, problem (8), (9) is unsolvable for arbitrary $w_{0}, w_{1} \in \mathfrak{U}$. Construct the set $\sigma_{n}^{L}(M)=\left\{\mu \in \mathbb{C}: \mu^{n} \in \sigma^{L}(M)\right\}$. This set is compact in $\mathbb{C}$ since the $L$-spectrum $\sigma^{L}(M)$ of the operator $M$ is compact. Consider a closed contour $\Gamma=\{|\mu|=$ $\left.R: R^{n}>a\right\}$ and construct the operator-functions

$$
V_{k}^{t}=\frac{1}{2 \pi i} \int_{\Gamma} \mu^{n-k-1}\left(\mu^{n} L-M\right)^{-1} L e^{\mu t} d \mu,
$$

where $m=0,1$, and the integral is understood in the Riemann sense.

Definition 2. The map $V^{\bullet} \in C^{\infty}(\mathbb{R} ; \mathcal{L}(\mathfrak{U}))$ is called a propagator of homogeneous equation (8), if the vector-function $w(t)=V^{t} v$ is a solution to (8) for all $v \in \mathfrak{U}$.

Theorem 2. [13] Let the operator $M$ be $(L, p)$-bounded. Then the operator-functions $V_{k}^{t}, k=0,1$ are propagators of homogeneous equation (8).

Theorem 3. [13] Let the operator $M$ be $(L, p)$-bounded. Then for any $N \in \mathcal{L}(\mathfrak{U}, \mathfrak{F})$ and a random process $w$ such that $(\mathbb{I}-Q) N g \in C^{p+2}\left(\mathbb{R}, \mathbf{F}_{\mathbf{K}} \mathbf{L}_{\mathbf{2}}\right)$ and $Q N g \in C\left(\mathbb{R}, \mathbf{F}_{\mathbf{K}} \mathbf{L}_{\mathbf{2}}\right)$, and for arbitrary independent random variables $w_{0}, w_{1} \in \mathbf{U}_{\mathbf{K}} \mathbf{L}_{\mathbf{2}}$, which are independent of $g$ for all fixed $t \in[0, \tau]$, there exists a unique solution $w$ to problem (8), (9) given by

$$
w(t)=\sum_{k=0}^{1} V_{k}^{t} w_{k}+\int_{0}^{t} V_{1}^{t-s} L_{1}^{-1} Q N g(s) d s-\sum_{q=0}^{p} H^{q} M_{0}^{-1}(\mathbb{I}-Q) N \stackrel{\circ}{g}(q)(t) .
$$

\section{Propagators of the Sobolev Stochastic Equation}

We consider a case when the domain $D$ is a parallelepiped. There are domains with an analytic boundary for which the operator $\Delta^{-1} \frac{\partial^{2}}{\partial z^{2}}$ where it has continuous spectrum. 
Consider a space over the domain $D$ such that the operator $\Delta^{-1}$ is a compact operator and the operator $\frac{\partial^{2}}{\partial z^{2}}$ is bounded, and therefore their composition is a compact operator. Therefore, the spectrum of $\Delta^{-1} \frac{\partial^{2}}{\partial z^{2}}$ is bounded. Later we will show that the $L$-spectrum of the operator $M$ coincides with the spectrum of the operator $\Delta^{-1} \frac{\partial^{2}}{\partial z^{2}}$. Let the domain $D$ be the parallelepiped $[0, a] \times[0, b] \times[0, c]$. Fix p $\in \mathbb{N}$ and define the spaces $\mathfrak{U}=\{u \in$ $\left.W_{2}^{p+2}(D): u(x, y, z, t)=0 \quad(x, y, z, t) \in \partial \Omega \times \mathbb{R}_{+}\right\}$and $\mathfrak{F}=W_{2}^{p}(D)$. The space $\mathfrak{U}$ is a separable Hilbert space by construction. Denote by $-\lambda_{l, m, n}^{2}=-\left(\frac{\pi l}{a}\right)^{2}-\left(\frac{\pi m}{b}\right)^{2}-\left(\frac{\pi n}{c}\right)^{2}$ the eigenvalues of the Dirichlet problem for the Laplace operator $\Delta$. Denote by $\varphi_{l, m, n}=$ $\sin \left(\frac{\pi l x}{a}\right) \sin \left(\frac{\pi m y}{b}\right) \sin \left(\frac{\pi n z}{c}\right)$ the eigenfunctions corresponding to $-\lambda_{l, m, n}^{2}$.

We introduce the $\mathfrak{U}$-valued random $K$-processes. The sequence $K$ is defined as follows: $K=\left\{\nu_{l, m, n}: \quad \nu_{l, m, n}=\lambda_{l, m, n}^{-2}\right\}$. By formula (7), we obtain the $\mathfrak{F}$-valued Wiener $K$-process in the form

$$
w_{K}(t)=\sum_{l, m, n=1}^{\infty} \nu_{l, m, n} \beta_{l, m, n}(t) \varphi_{l, m, n}
$$

where $\beta_{l, m, n}(t)$ is a product of three independent one-dimensional Wiener processes (6).

Define the operators

$$
L=\Delta, \quad M=-F^{2} \frac{\partial^{2}}{\partial z^{2}}, \quad N=\mathbb{I}
$$

as elements of the space $\mathcal{L}\left(\mathbf{U}_{\mathbf{K}} \mathbf{L}_{\mathbf{2}}^{\mathbf{0}} ; \mathbf{F}_{\mathbf{K}} \mathbf{L}_{\mathbf{2}}\right)$ by virtue of Lemma 1. Also, define the inhomogeneity function as the Nelson-Gliklikh derivative of the Wiener process

$$
g=\stackrel{\circ}{w_{K}}(t)
$$

Therefore, we reduce mathematical model (3) - (5) to Cauchy problem (9) for abstract equation (8).

Since $\left\{\varphi_{l, m, n}\right\} \subset C^{\infty}(D)$, then

$$
\mu^{2} L-M=\sum_{l, m, n=1}^{\infty}\left[-\lambda_{l, m, n}^{2} \mu^{2}-F^{2}\left(\frac{\pi n}{c}\right)^{2}\right]<\varphi_{l, m, n}, \cdot>\varphi_{l, m, n}
$$

where $\langle\cdot, \cdot\rangle$ is the inner product in $L^{2}(D)$. The equation

$$
\lambda_{l, m, n}^{2} \mu^{2}+F^{2}\left(\frac{\pi n}{c}\right)^{2}=0
$$

determines the relative spectrum of the operator $M$ :

$$
\mu_{l, m, n}^{ \pm}= \pm \frac{F \pi n}{c \sqrt{\lambda_{l, m, n}^{2}}} i
$$

Therefore, $\sigma^{L}(\vec{M})=\left\{\mu_{l, m, n}^{ \pm}\right\}$is the $L$-spectrum of the operator $M$ and is bounded.

Construct the propagators according to the Theorem 2. Since the relative spectrum of the operator $M$ is discrete, we obtain

$$
\begin{aligned}
& V_{0}^{t} w_{0}=\sum_{l, m, n=1}^{\infty} \cos \left(\frac{F \pi n}{c \sqrt{\lambda_{l, m, n}^{2}}} t\right)<\varphi_{l, m, n}, w_{0}>\varphi_{l, m, n}, \\
& V_{1}^{t} w_{1}=\sum_{l, m, n=1}^{\infty} \frac{F \pi n}{c \sqrt{\lambda_{l, m, n}^{2}}} \sin \left(\frac{F \pi n}{c \sqrt{\lambda_{l, m, n}^{2}}} t\right)<\varphi_{l, m, n}, w_{1}>\varphi_{l, m, n} .
\end{aligned}
$$


Due to the fact that "white noise" $\stackrel{\circ}{w}_{K}(t)$ is not differentiable with $t=0$, the integral in formula (10) does not make sense and conditions of the Theorem 3 are not satisfied. In order to overcome this difficulty, we use the method proposed in [10]. In order to use this method, we transform the second term from the right-hand side of (10) as follows:

$$
\begin{gathered}
\int_{\varepsilon}^{t} V_{1}^{t-s} \stackrel{\circ}{w_{K}}(t)(s) d s=-V_{1}^{t-\varepsilon} w_{K}(t)-\int_{\varepsilon}^{t} \frac{d}{d s}\left(V_{0}^{t-s}\right) w_{K}(s) d s= \\
=-V_{1}^{t-\varepsilon} w_{K}(\varepsilon)+\int_{\varepsilon}^{t} V_{0}^{t-s} w_{K}(s) d s .
\end{gathered}
$$

In this case, integration by parts makes sense for any $\varepsilon \in(0, t), t \in \mathbb{R}_{+}$, by virtue of the definition of the Nelson-Gliklikh derivative. If $\varepsilon \rightarrow 0$, then we obtain

$$
\int_{0}^{t} V_{1}^{t-s} w_{K}^{\circ}(s) d s=\int_{0}^{t} V_{0}^{t-s} w_{K}(s) d s .
$$

Therefore, the conditions of Theorem 3 are fulfilled. Hence, there exists the unique solution to problem $(2)-(5)$ given by

$$
w(x, t)=V_{0}^{t} w_{0}+V_{1}^{t} w_{1}+\int_{0}^{t} V_{0}^{t-s} w_{K}(s) d s .
$$

Acknowledgments. This work was supported by a grant from the President of the Russian Federation for state support of leading scientific schools of the Russian Federation (SSh-2553.2020.8).

\section{References}

1. Brekhovskikh L.M., Goncharov V.V. Vvedenie v mekhaniku sploshnykh sred (v prilozhenii $k$ teorii voln) [Introduction to the Mechanics of Continuous Media (as Applied to the Theory of Waves)]. Moscow, Nauka, 1982. (in Russian)

2. Sobolev S.L. [On a New Problem of Mathematical Physics]. Izvestiya Akademii Nauk SSSR, 1954, vol. 18, no. 1, pp. 3-50. (in Russian)

3. Fokin M.V. Hamiltonian Systems in the Theory of Small Oscillations of a Rotating Ideal Fluid I. Siberian Advances in Mathematics, 2002, vol. 12, no. 1, pp. 1-50.

4. Gliklikh Yu.E. Global and Stochastic Analysis with Applications to Mathematical Physics. London, Springer, 2011. DOI: 10.1007/978-0-85729-163-9

5. Gliklikh Yu.E. The Study of Leontieff Type Equations with White Noise by the Methods of Mean Derivatives of Stochastic Processes. Bulletin of the South Ural State University. Series: Mathematical Modelling, Programming and Computer Software, 2012, no. 27, pp. 24-34. (in Russian)

6. Nelson E. Dynamical Theory of Brownian Motion. Princeton, Princeton University Press, 1967.

7. Kovacs M., Larsson S. Introduction to Stochastic Partial Differential Equations. Proceedings of New Directions in the Mathematical and Computer Sciences, 2007, vol. 4, pp. 159-232.

8. Melnikova I.V., Alshanskiy M.A. The Generalized Well-Posedness of the Cauchy Problem for an Abstract Stochastic Equation with Multiplicative Noise. Proceedings of the Steklov Institute of Mathematics (Supplementary Issues), 2013, vol. 280, pp. 134-150. DOI: $10.1007 / 978-3-0348-0585-8$ 
9. Sagadeeva M.A. Reconstruction of Observation from Distorted Data for the Optimal Dynamic Measurement Problem. Bulletin of the South Ural State University. Series: Mathematical Modelling, Programming and Computer Software, 2019, vol. 12, no. 2, pp. 82-96. (in Russian) DOI: $10.14529 / \mathrm{mmp} 190207$

10. Sviridyuk G.A., Manakova N.A. The Dynamical Models of Sobolev Type with ShowalterSidorov Condition and Additive "Noise". Bulletin of the South Ural State University. Series: Mathematical Modelling, Programming and Computer Software, 2014, vol. 7, no. 1, pp. 90103. (in Russian) DOI: $10.14529 / \operatorname{mmp} 140108$

11. Favini A., Sviridyuk G.A., Manakova N.A. Linear Sobolev Type Equations with Relatively p-Sectorial Operators in Space of "Noises". Abstract and Applied Analysis, 2015, vol. 2015, pp. 1-8. DOI: $10.1155 / 2015 / 697410$

12. Zamyshlyaeva A.A., Sviridyuk G.A. The Linearized Benney-Luke Mathematical Model with Additive White Noise. Semigroups of Operators. Theory and Applications, 2015, vol. 113, pp. 327-337. DOI: 10.1007/978-3-319-12145-1_21

13. Favini A., Sviridyuk G.A., Zamyshlyaeva A.A. One Class of Sobolev Type Equations of Higher Order with Additive "White Noise". Communications on Pure and Applied Analysis, 2016, vol. 15, no. 1, pp. 185-196. DOI: 10.3934/cpaa.2016.15.185

14. Favini A., Zagrebina S.A., Sviridyuk G.A. Multipoint Initial-Final Value Problems for Dynamical Sobolev-Type Equations in the Space of "Noises". Electronic Journal of Differential Equations, 2018, vol. 2018, p. 128.

15. Sviridyuk G.A., Zamyshlyaeva A.A., Zagrebina S.A. Multipoint Initial-Final Problem for One Class of Sobolev Type Models of Higher Order with Additive "White Noise". Bulletin of the South Ural State University. Series: Mathematical Modelling, Programming and Computer Software, 2018, vol. 11, no. 3, pp. 103-117. DOI: 10.14529/mmp180308

16. Kitaeva O.G., Shafranov D.E., Sviridyuk G.A. Exponential Dichotomies in BarenblattZheltov-Kochina Model in Spaces of Differential Forms with "Noise". Bulletin of the South Ural State University. Series: Mathematical Modelling, Programming and Computer Software, 2019, vol. 12, no. 2, pp. 47-57. DOI: 10.14529/mmp190204

Received January 20, 2020

УДК 517.9

DOI: $10.14529 / \mathrm{mmp} 200203$

\title{
СТОХАСТИЧЕСКАЯ МАТЕМАТИЧЕСКАЯ МОДЕЛЬ ВНУТРЕННИХ ВОЛН
}

\author{
Е.В. Бъчков ${ }^{1}$, А.В. Богомолов ${ }^{2}$, К.Ю. Котлованов ${ }^{1}$ \\ ${ }^{1}$ Южно-Уральский государственный университет, г. Челябинск, \\ Российская Федерация \\ ${ }^{2}$ Санкт-Петербургский институт информатики и автоматизации Российской \\ академии наук, г. Санкт-Петербург, Российская Федерация
}

В работе проведено исследование математической модели внутренних гравитационных волн с аддитивным «белым шумом», который моделирует случайные неоднородности среды и флуктуации. Математическая модель строится на стохастическом 
уравнении Соболева, краевых условиях Дирихле и начальном условии Коши. Математическая модель строится на стохастическом уравнении Соболева, краевых условиях Дирихле и начальном условии Коши. Уравнение Соболева получено из предположения о распространении волн в однородной несжимаемой вращающейся с постоянной угловой скоростью жидкости. Решение этой задачи называется инерционной (гироскопической) волной, поскольку она возникает в силу закона Архимеда и под воздействием сил инерции. Под «белым шумом» мы подразумеваем производную Нельсона - Гликлиха винеровского процесса. Исследование проведено в рамках теории относительно ограниченных операторов и теории стохастических уравнений соболевского типа и теории (полу)групп операторов. Показано, что относительный спектр оператора ограничен, и построено решение в операторном виде.

Ключевые слова: относительно ограниченные операторов; уравнение Соболева; пропагаторы; «белый шум»; производная Нельсона - Гликлиха.

\section{Литература}

1. Бреховских, Л.М. Введение в механику сплошных сред / Л.М. Бреховских, В.В. Гончаров. - М.: Наука, 1982.

2. Соболев, С.Л. Об одной новой задаче математической физики / С.Л. Соболев // Известия АН СССР. Серия: Математическая. - 1954. - Т. 18. - С. 3-5.

3. Фокин, М.В. Гамильтоновы системы в теории малых колебаний вращающейся идеальной жидкости. I / М.В. Фокин // Математические труды. - 2001. - Т. 4, № 2. - С. 155-206.

4. Gliklikh, Yu.E. Global and Stochastic Analysis with Applications to Mathematical Physics / Yu.E. Gliklikh. - London; Dordrecht; Heidelberg; N.Y.: Springer, 2011.

5. Гликлих, Ю.Е. Изучение уравнений леонтьевского типа с белым шумом методами производных в среднем случайных процессов / Ю.Е. Гликлих // Вестник ЮУрГУ. Серия: Математическое моделирование и программирование. - 2012. - № 27 (286), вып. 13. C. 24-34.

6. Nelson, E. Dynamical Theory of Brownian Motion / E. Nelson. - Princeton: Princeton University Press, 1967.

7. Kovacs, M. Introduction to Stochastic Partial Differential Equations / M. Kovacs, S. Larsson // Proceedings of New Directions in the Mathematical and Computer Sciences. - 2007. V. 4. - P. 159-232.

8. Мельникова, И.В. Обобщенная корректность задачи Коши для абстрактного стохастического уравнения с мультипликативным шумом / И.В. Мельникова, М.А. Альшанский // Труды института математики и механики УрО РАН. - 2012. - Т. 18, № 1. - С. 251-267.

9. Сагадеева, М.А. Построение наблюдения для задачи оптимального динамического измерения по искаженным данным / М.А. Сагадеева // Вестник ЮУрГУ. Серия: Математическое моделирование и программирование. - 2019. - Т. 12, № 2. - С. 82-96.

10. Sviridyuk, G.A. Динамические модели соболевского типа с условием Шоуолтера - Сидорова аддитивными шумами / Г.А. Свиридюк, Н.А. Манакова // Вестник ЮУрГУ. Серия: Математическое моделирование и программирование. - 2014. - Т. 7, № 1. C. 90-103.

11. Favini, A. Linear Sobolev Type Equations with Relatively p-Sectorial Operators in Space of «Noises»/ A. Favini, G.A. Sviridyuk, N.A. Manakova // Abstract and Applied Analysis. 2015. - V. 2015. - P. 1-8.

12. Zamyshlyaeva, A.A. The Linearized Benney - Luke Mathematical Model with Additive White Noise / A.A. Zamyshlyaeva, G.A. Sviridyuk // Semigroups of Operators. Theory and Applications. - 2015. - V. 113. - P. 327-337. 
13. Favini, A. One Class of Sobolev Type Equations of Higher Order with Additive «White Noise» / A. Favini, G.A. Sviridyuk, A.A. Zamyshlyaeva // Communications on Pure and Applied Analysis. - 2016. - V. 15, № 1. - P. 185-196.

14. Favini, A. Multipoint Initial-Final Value Problems for Dynamical Sobolev-Type Equations in the Space of «Noises» / A. Favini, S.A. Zagrebina, G.A. Sviridyuk // Electronic Journal of Differential Equations. - 2018. - V. 2018. - P. 128.

15. Sviridyuk, G.A. Multipoint Initial-Final Problem for One Class of Sobolev Type Models of Higher Order with Additive «White Noise»/ G.A. Sviridyuk, A.A. Zamyshlyaeva, S.A. Zagrebina // Вестник ЮУрГУ. Серия: Математическое моделирование и программирование. - 2018. - Т. 11, № 3. - С. 103-117.

16. Kitaeva, O.G. Exponential Dichotomies in Barenblatt - Zheltov - Kochina Model in Spaces of Differential Forms with «Noise» / O.G. Kitaeva, D.E. Shafranov, G.A. Sviridyuk // Вестник ЮУрГУ. Серия: Математическое моделирование и программирование. - 2019. - Т. 12, № 2. - C. $47-57$.

Евгений Викторович Бычков, кандидат физико-математических наук, кафедра «Уравнения математической физики», Южно-Уральский государственный университет (г. Челябинск, Российская Федерация), bychkovev@susu.ru.

Алексей Валерьевич Богомолов, доктор технических наук, профессор, лаборатория автоматизации научных исследований, Санкт-Петербургский институт информатики и автоматизации Российской академии наук (г. Санкт-Петербург, Российская Федерация), a.v.bogomolov@gmail.com.

Константин Юрьевич Котлованов, аспирант, кафедра «Уравнения математической физики», Южно-Уральский государственный университет (г. Челябинск, Российская Федерация), kotlovanovki@susu.ru.

Поступила в редакиию 20 января 2020 г. 